\title{
Protective Effect of Combined Melatonin and $\alpha$-Tocopherol Administration in Spinal Cord Ischemia-Reperfusion Injury in Rat
}

\author{
Efecto Protector de la Administración Combinada de Melatonina y $\alpha$-Tocoferol \\ en la Lesión por Isquemia-Reperfusión de la Médula Espinal en Ratas
}

Mohamed Darwesh Morsy ${ }^{1,2}$; Salah Omar Bashir'; Dalia Fathy Al Agamy² \& Hesham Ahmed Diaa²

MORSY, M. D.; BASHIR, S. O.; AL AGAMY, D. F. \& DIAA, H. A. Protective effect of combined melatonin and $\boldsymbol{\alpha}$-tocopherol administration in spinal cord ischemia-reperfusion injury in rat. Int. J. Morphol., 37(2):428-437, 2019.

SUMMARY: Oxidative stress and inflammation are the key players in the development of motor dysfunction post-spinal cord ischemic reperfusion injury (SC-IRI). This study investigated the protective effect of concomitant pre-administration of melatonin and alpha-tocopherol on the early complications (after 48 hours) of spinal cord IRI injury in rats. Melatonin or $\alpha$-tocopherol were preadministered either individually or in combination for 2 weeks, then rats were exposed SC-IRI. Neurological examinations of the hind limbs and various biochemical markers of oxidative stress and inflammation in the SC tissue were assessed. Solely pre-administration of either melanin or $\alpha$-tocopherol significantly but partially improved motor and sensory function of the hind limbs mediated by partial decreases in SC levels of MDA, AOPP and PGE2 levels and activities of SOD, partial significant decreases in plasma levels of total nitrate/nitrite and significant increases in AC activity of GSH-Px. However, combination therapy of both drugs resulted in the maximum improvements in all neurological assessments tested and biochemical endpoints. In conclusion, by their synergistic antioxidant and antiinflammatory actions, the combination therapy of melatonin and $\alpha$-tocopherol alleviates SC-IRI induced paraplegia.

KEY WORDS: Spinal cord ischemic reperfusion injury; Melatonin; alpha-tocopherol, Oxidative stress; Paraplegia.

\section{INTRODUCTION}

Currently, it is estimated that more than 500,000 patients are diagnosed with spinal cord injury (SCI) every year worldwide (Yang et al., 2016). Unfortunately, those patients experience serious complications and impairments, including partial to complete sensory loss, paraplegia, and neurogenic bladder and bowel dysfunction (Morsy et al., 2010). This has been also shown in our labs as well as by other authors in experimental animals exposed to SCI or SCI-ischemia reperfusion (CS-IRI) (Bashir et al., 2012). Secondary injury stage post-SC damage is the major event leading to worsening the SC damage and motor function. This occurs within minutes to hours after the primary insult as a complex array of multiple interconnected pathophysiological processes including oxidative stress, inflammation, excitotoxicity (Yang et al.).

Indeed, investigation of the molecular mechanisms underlying SC-IRI in both animals and human revealed crucial roles of the increase in intracellular calcium levels, overproduction of reactive oxygen species (ROS), enhanced lipid peroxidation, inflammation and apoptosis (Sakurai $e t$ al., 1998). In this regard, SC-IRI induced oxidative stress exaggerated the expression of cyclooxygenase (COX) enzyme (Kaur \& Sanyal, 2010) leading to massive increases in spinal levels of prostaglandin E2, a major inflammatory mediator in this tissue and the key factor in SC-IRI induced neurological deficits in hind limbs (Morsy et al.). In addition, prostaglandin $\mathrm{E} 2$ and the associated inflammatory reaction can generate high levels of nitric oxide (NO), which can further reacts with superoxide anion leading to the formation of peroxynitrite (NOO-), a highly toxic free radical, indicating a vicious cycle between spinal SC-IRI induced oxidative stress and inflammation (Bao \& Liu, 2003).

With our current understanding of the pathophysiology of the disease, innovative continuous attempts are currently run and being given more attention in the hope that an increasing number of therapies for SCI will emerge from the animal's investigations. The effects of currently available therapies are generally limited and cautious with their limited output

\footnotetext{
${ }^{1}$ Department of Physiology, College of Medicine, King Khalid University, Abha, Saudi Arabia.

${ }^{2}$ Department of Physiology, College of Medicine, Menoufia University, Shebeen Alkoom, Egypt.
} 
and their associated unwanted side effects (Saito et al., 2011). For example, most of the available regenerative therapy including adoptive cell transplantation needs further investigation and consideration to overcome the effects of inhibitory molecules, the glial scar, and use of tissue engineering strategies (Bernes \& Karin, 1997; Zhang et al., 2013). In addition, the use of glucocorticoids is often linked to a series of harmful adverse side effects after prolonged use including the dose-dependent brittle bones and increase in weight gain (Yang et al.). Also, this could be attributed to the single use of either antioxidant or antiinflammatory agents. In this regard, the accumulative evidence is currently recommending the use of a combination therapy of various individual effective drugs with various targets as a new strategy for the treatment of numerous disorders (CDER, 2013).

Melatonin, a pineal gland-derived hormone, as well as its metabolites, have been well described as a potent antioxidant agent against both oxidative and nitrosative stress (Tan et al., 2000) as well as an anti-inflammatory agents. Additionally, melatonin has the ability to facilitate angiogenesis and wound healing (Szczepanik, 2007). The vast and ubiquitous distribution of melatonin receptors within the nervous system including the brain and the SC indicates its role in providing neuroprotection (Silva et al., 2005). Indeed, in experimental animal models of SCI model, melatonin promoted full repair of the damaged blood-SC barrier (Wu et al., 2014). Also, pre-treatment with melatonin fully restored SC GSH levels but partially reduced the levels of malondialdehyde (MDA) and cleaved caspase-3 activity after 48 hours of SC-IRI induction (Aydemir et al., 2016). Similar results were obtained by other investigators (Aghazadeh et al., 2007). These data indicate that the addition of any other potent inflammatory or antioxidant agent may act synergistically with melatonin to afford a full protection against SCI-IRI.

On the other hand, $\alpha$-tocopherol is one of the most potent biological a lipid-soluble chain-breaking antioxidant and ROS scavenger in most the body tissues including the neural tissue (Tan et al., 2007; Birben et al., 2012). Interestingly, by acting through inhibiting lipid peroxidation and ROS scavenging, $\alpha$-tocopherol supplementation significantly reduced the motor disturbance induced by SCI (Iwasa et al., 1989) and significantly but partially improved the SC evoked potentials of both amplitude and latency in control rats (Iwasa \& Ikata, 1988). Also, $\alpha$-tocopherol has reparative effects on SCI and it partially enhanced mean motor score in SCI patients. In our labs, we have also demonstrated that administration of a calibrated dose of $\alpha$ tocopherol to rats significantly but partially resorted motor and sensory function of the hind limbs after SC-IRI by partial amelioration of NO and PGE2 production and complete inhibition of increased lipid peroxidation (Morsy et al.).

Given the partial protective effects of melatonin and alpha-tocopherol, the present study was designed to explore the possible prophylactic effect of combined melatonin and $\alpha$-TOL administration prior to the onset of SC-IRI in rats from perspective of their combined anti-oxidant and antiinflammatory actions.

\section{MATERIAL AND METHOD}

Animals and experimental procedure. pProcedures of this randomized controlled animal experiment study were approved by the ethical committee of the College of Medicine at King Khalid University, Abha, Saudi Arabia and follow the animal use guidelines established by the US National Institutes of Health (NIH publication No. 85-23, revised 1996). Healthy adult male Sprague-Dawley rats were adapted together for a one week period in a temperature $\left(23 \pm 1{ }^{\circ} \mathrm{C}\right)$, humidity $(40-65 \%)$ and 12 -h light/dark cycle a controlled room. During the adaptation and experimental period, animals were fed semipurified standard AIN-93G diet and had free access to drinking water ad libitum. Melatonin (Sigma, St Louis, USA) was always dissolved fresh in normal saline whereas $\alpha$-tocopherol (Sigma, St Louis, USA) was always diluted in $0.1 \mathrm{ml}$ of coconut oil to their final concentrations. Rats were randomly divided into five groups ( $\mathrm{n}=10$ /group) as:

1) a control group: which underwent no surgery and received normal saline (i.p) as a vehicle,

2) a sham-operated group: which were subjected to laparotomy procedure but without clamping of the aorta, 3) an ischemic reperfusion injury-induced group (SC-IRI): which were subjected to laparotomy and clamping the aorta as explained below,

4) a melatonin pretreated and then SC-IRI-induced group (SC-IRI+Mel): which were pretreated with melatonin $15 \mathrm{mg} /$ $\mathrm{kg}(1 \mathrm{x} /$ day, i.m.) for 2 weeks then exposed to SC-IRI. Melatonin dose was selected based on the study of (Gül et al., 2005) who showed the partial protective effect of melatonin on SC-IRI.

5) an $\alpha$-tocopherol pretreated and then SC-IRI-induced group (SC-IRI $+\alpha$-tocopherol): Which were pretreated with an oral dose of $\alpha$-tocopherol ( $600 \mathrm{mg} / \mathrm{kg}, 2 \mathrm{x} /$ week, i.p.) for 2 weeks and then exposed to SC-IRI. Such dose was selected based on our study (Morsy et al.) where we have shown that $\alpha$ tocopherol at this dose for 2 weeks was able to partially restore motor and sensory functions in the hind limbs after SC-IRI. 
6) a melatonin $+\alpha$-tocopherol pretreated rats and then SCIRI-induced group (SC-IRI+Mel+ $\alpha$-tocopherol): Which were pretreated with a concomitant dose of melatonin and $\alpha$-tocopherol using same routs described in groups 4 and 5, respectively, for 2 weeks and then exposed to SC-IRI.

Induction of SC-IRI. Induction of SC-IRI in rats was done as previously described by us and other (Akgun et al., 2004; Morsy et al.). In brief, unventilated rats anesthetized with ketamine $(50 \mathrm{mg} / \mathrm{kg}$; i.m.) and their femoral and carotid arteries were canulated to measure distal arterial pressure (DAP) and proximal arterial pressure (PAP), respectively. The midline laparotomy was conducted to locate the abdominal aorta which was isolated from the surrounded connective tissue. In SCIRI induced groups, aortic cross-clamping was achieved by placing the clamp over the abdominal aorta under the left renal vein and just above the bifurcation for 45 minutes. This has been confirmed by the immediate sustained decreased in DAP. In this procedure and to maintain the PAP approximately at $40 \mathrm{mmHg}$ during the occlusion of the abdominal aorta, the blood was collected in a collecting circuit filled with heparinized saline $\left(4 \mathrm{U} / \mathrm{ml}\right.$ of saline) and maintained at $37^{\circ} \mathrm{C}$, which was reperfused back to the rats over a period of 1 minute after the clamp release. Similar procedure without clamping was used in the sham-operated rats. During the surgery, body temperature was continuously monitored and maintained at $37^{\circ} \mathrm{C}$ and the rat was injected with heparin $(150 \mathrm{IU} / \mathrm{kg})$ at the beginning of the surgery. Wounds were sutured and all animals were allowed to recover in their cages. Rats included in this study were those which developed complete hind limb paralysis, hematuria or $25 \%$ reduction in their body weight, after 24 hours. Then these animals were killed by an overdose of thiopental sodium (75 mg/kg i.p.) followed by cervical dislocation.

Neurological assessment. In this study, we have assessed the hind limbs neurologic function by measuring the motor and sensory function as well as the placing/stepping reflex (SPR) function as previously described in our previous work (Morsy et al.). In this test, motor function was assessed in accordance with Tarlov's Scoring System (Tarlov, 1972) by giving each rat a score between 0.0 to 5 , based on the following criteria 1 ) score $0=$ no voluntary hind limb movement, 2) score $1=$ movement of joints perceptible, 3 ) score $2=$ active movement but unable to sit without assistance, 4 ) score $3=$ able to sit but unable to hop, 5) score $4=$ weak hop and 6) score $5=$ complete recovery of hind limb function. Similarly, a score of 0-1 was given to assess the sensory function of one hind limb withdrawal from a painful stimulus where score 0 indicates no response to noxious stimulus and score 1 indicates a withdrawal response. Dragging the dorsum of the hind paw along the edge of a surface procedure was used to assess the placing/stepping reflex (SPR) of each rat. In this test, this normally evokes a coordinating lifting and placing response which was graded as follows: $0=$ normal; $1=$ weak; and $2=$ no stepping (Marsala \& Yaksh, 1994).

Blood sampling and biochemical measurements . Fortyeight hours after the induction of SC-IRI, overnight fasted rats were anesthetized with sodium pentobarbital $(50 \mathrm{mg} / \mathrm{kg}$, i.p.) and blood samples were collected directly into EDTA tubes, centrifuged at $1000 \mathrm{rpm}$ for $15 \mathrm{~min}$ to collect plasma which was then stored at $-80{ }^{\circ} \mathrm{C}$ for any further use. Plasma levels of nitrite and nitrate were measured using Cayman assay kit (cat. no. 780001). This kit utilizes 2 reaction in which the first reaction converts nitrate to nitrite using nitrate reductase and the second reaction utilizes Griess Reagents to convert nitrite into a deep purple azo compound that can be read at $540 \mathrm{~nm}$. All procedures followed the manufacturer's instruction and were performed in duplicates. Results are presented as total levels of nitrate+nitrite and expressed as mM.

\section{Preparation of lumber spinal cord homogenates for} Histopathological examination and biochemical measurements. Rats were killed using cervical dislocation under anesthesia. Lumber spinal cord segments ( $\mathrm{L} 3^{\text {rd }}, 4^{\text {th }}$ and $\left.5^{\text {th }}\right)$ from all rats were collected. Spinal cord segments from four rats in each group were used for histopathological examination using haematoxlin and eosin stains under light microscope, while the SC segments from the other 6 rats were homogenized in ice-cold lysis buffer $(\mathrm{pH}$ 7.4) consisting of $0.1 \mathrm{M}$ phosphate, $1 \mathrm{mM}$ EDTA, $10 \mathrm{mM}$ indomethacin using a tube pestle and acetone was added in a ratio of $2: 1 \mathrm{v}: \mathrm{v}$ to the homogenate. Then, all homogenates were centrifuged at 1500 rpm for 10 min at $4{ }^{\circ} \mathrm{C}$ to collect supernatant which was stored at $-80^{\circ} \mathrm{C}$.

Levels of malondialdehyde (MDA) as a marker of lipid peroxidation were measured using an assay kit (cat no. NWKMDA01, NWLSS, USA). Levels of advanced oxidation protein products (AOPP) as a marker of protein oxidation and oxidative stress in the $\mathrm{SC}$ of rats were determined using OxiSelect ${ }^{\mathrm{TM}}$ AOPP Assay Kit (cat. no. STA- 318, Cell Biolabs, $\mathrm{Ca}$, USA). Superoxide dismutase (SOD) and glutathione peroxidase (GSH-Px) activities were measured using assay kits (Cat. No. 706002 \&703102, respectively, Cayman Chemical, Ann Arbor, MI, USA). Levels of prostaglandin E2 (PGE2) were measured by an ELISA kit (cat. no. MBS262150, MyBioSource, CA, USA)

Statistical analysis. All statistical analysis was done using GraphPad Prism statistical software package, version 6 (GraphPad Prism, San Diego, CA). All data were analyzed using one-way analysis of variance (ANOVA) followed by post-hoc Scheffe test. Data are expressed as means \pm SD and a value of $\mathrm{P}$-values $<0.05$ were considered statistically significant. 


\section{RESULTS}

Motor, SPR and sensory assessment. SC-IRI induced rats had significantly decreased scores of the motor and sensory function as well as SPR as compared to control or shamoperated rats. Pretreatment with melatonin or $\alpha$-tocopherol significant but partially increased the scores of all the above mentioned neurological test as compared to SC-IRI-induced rats, with no significant differences in all these tests when these 2 groups were compared to each other. On the other hand, concomitant pre-administration of both melatonin and $\alpha$-Tocopherol produced the maximum improvements in the motor, sensory and SPR scores in the treated rats as compared to SC-IRI-induced rats, values which were significantly higher than their corresponding scores measured using their individual administration (Tables I and II).

Plasma levels of total nitrate/nitrite. Significant increases in serum levels of total nitrate/nitrite levels were seen in SC-IRI -induced rats as compared to control or sham- operated rats. However, significant decreases in the levels of plasma levels of total nitrate/nitrite were achieved in both SC-IRI induced rats treated with either melatonin or $\alpha$ tocopherol as compared to SC-IRI model rats. ANOVA analysis revealed no significant changes in the plasma levels of total nitrate/nitrite when SC-IRI+Melatonin was compared with SC-IRI+ $\alpha$-Tocopherol -treated groups were compared with each other. On the other hand, concomitant administration of both drugs significantly lowered and normalized the levels of plasma total nitrate/nitrite as compared to SC-IRI and shamoperated rats, respectively (Fig. 1A).

Oxidative stress parameters and PGE2 levels in lumber spinal cord homogenates. Levels of PGE2 (Fig. 1B), MDA, and AOPP (Fig. 2A, B) and the activities of SOD (Fig. 3A) were significantly elevated whereas activities of GSH-Px (Fig. 3B) were significantly decreased in the SC homogenates of SC-IRI-induced rats as compared to control sham-operated rats. Individual pre-administration of melatonin or $\alpha$-tocopherol significantly but partially lowered levels of PGE2, MDA, and AOPP and activities of SOD and

Table I. Average scores of motor function assessment in all groups of rats.

\begin{tabular}{ccccccc}
\hline Rats no. & control & Sham & SC-IRI & SC-IRI+Mel & $\begin{array}{c}\text { SC-IRI+ } \\
\text { oxtocopherol }\end{array}$ & $\begin{array}{c}\text { SC-IRI+Mel+ ox- } \\
\text { tocopherol }\end{array}$ \\
\hline 1 & 5 & 5 & 1 & 4 & 3 & 4 \\
2 & 5 & 5 & 0 & 4 & 3 & 5 \\
3 & 5 & 5 & 2 & 4 & 4 & 4 \\
4 & 5 & 5 & 2 & 3 & 4 & 4 \\
5 & 5 & 5 & 1 & 3 & 4 & 3 \\
6 & 5 & 5 & 3 & 3 & 4 & 5 \\
7 & 5 & 5 & 2 & 3 & 3 & 4 \\
8 & 5 & 5 & 2 & 3 & $3.5^{\text {abc }}$ & $4.1^{\text {abcd }}$ \\
Mean & 5.0 & 5.0 & $1.6^{\text {ab }}$ & $3.4^{\text {abc }}$ & 0.23 & \\
SD & 0.00 & 0.00 & 0.92 & 0.52 & & 0.24 \\
\hline
\end{tabular}

Results are expressed as means $\pm \mathrm{SD}(\mathrm{n}=10)$. Significance was considered when P value was $<0.05$. a: vs. Control; b: vs. Sham-operated; c: vs. SC-IRI; d: vs. SC-IRI+melatonin; e: vs. SC-IRI+ $\alpha$-Tocopherol. SC-IRI: spinal cord ischemic reperfusion injury-induced group; Mel: melatonin.

Table II. Scores of Sensory function and placing/Stepping reflex in all groups of rat.

\begin{tabular}{|c|c|c|c|c|c|c|c|}
\hline & & control & sham & SC-IRI & $\begin{array}{l}\text { SC-IRI } \\
+ \text { Mela }\end{array}$ & 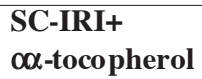 & $\begin{array}{l}\text { SC-IRI+Mel+ } \alpha o- \\
\text { tocopherol }\end{array}$ \\
\hline \multirow{2}{*}{ 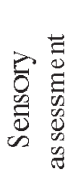 } & Normal & $\begin{array}{c}10 \\
(100 \%)\end{array}$ & $\begin{array}{c}10 \\
(100 \%)\end{array}$ & $\begin{array}{c}3 \mathrm{a} \\
(33.3 \%)\end{array}$ & $\begin{array}{c}7 \mathrm{a}^{\mathrm{b}} \\
(77.7 \%)\end{array}$ & $\begin{array}{c}6 \mathrm{a}^{\mathrm{b}} \\
(66.6 \%)\end{array}$ & $\begin{array}{c}9 \mathrm{~b}^{\mathrm{c}, \mathrm{d}} \\
(100 \%)\end{array}$ \\
\hline & Affected & $\begin{array}{c}0 \\
(0 \%)\end{array}$ & $\begin{array}{c}0 \\
(0 \%)\end{array}$ & $\begin{array}{c}5^{\mathrm{ab}} \\
(55.5 \%)\end{array}$ & $\begin{array}{c}2 \mathrm{a}^{\mathrm{bc}} \\
(33.3 \%)\end{array}$ & $\begin{array}{c}4 \mathrm{a}^{\mathrm{bcd}} \\
(66.6 \%)\end{array}$ & $\begin{array}{l}0^{\text {cde }} \\
(0 \%)\end{array}$ \\
\hline \multirow{3}{*}{ 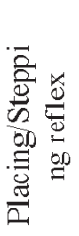 } & Normal & $\begin{array}{c}10 \\
(100 \%)\end{array}$ & $\begin{array}{c}10 \\
(100 \%)\end{array}$ & $\begin{array}{c}3^{\mathrm{ab}} \\
(33.3 \%)\end{array}$ & $\begin{array}{c}5 \mathrm{a}^{\mathrm{bc}} \\
(55.5 \%)\end{array}$ & $\begin{array}{c}7 \mathrm{a}^{\mathrm{bcd}} \\
(77.7 \%)\end{array}$ & $\begin{array}{c}8^{\text {abcde }} \\
(88.9 \%)\end{array}$ \\
\hline & Impaired & $\begin{array}{c}0 \\
(0 \%)\end{array}$ & $\begin{array}{c}0 \\
(0 \%)\end{array}$ & $\begin{array}{c}2^{\mathrm{ab}} \\
(33.3 \%)\end{array}$ & $\begin{array}{c}3^{\mathrm{ab}} \\
(33.3 \%)\end{array}$ & $\begin{array}{c}2 \mathrm{a}^{\mathrm{bcd}} \\
(22.2 \%)\end{array}$ & $\begin{array}{c}1^{\text {abcde }} \\
(11.1 \%)\end{array}$ \\
\hline & Lost & $\begin{array}{c}0 \\
(0 \%)\end{array}$ & $\begin{array}{c}0 \\
(0 \%)\end{array}$ & $\begin{array}{c}3^{\mathrm{ab}} \\
(33.3 \%)\end{array}$ & $\begin{array}{c}1 \mathrm{a}^{\mathrm{bc}} \\
(11.1 \%)\end{array}$ & $\begin{array}{c}1^{\mathrm{abc}} \\
(11.1 \%)\end{array}$ & $\begin{array}{c}0^{\text {cde }} \\
(0 \%)\end{array}$ \\
\hline
\end{tabular}

Results are expressed as the ratio of the control. a: vs. Control; b: vs. Sham-operated; c: vs. SC-IRI; d: vs. SC-IRI+melatonin; e: vs. SC-IRI+ $\alpha$-Tocopherol. SC-IRI: spinal cord ischemic reperfusion injury-induced group; Mel: melatonin. 


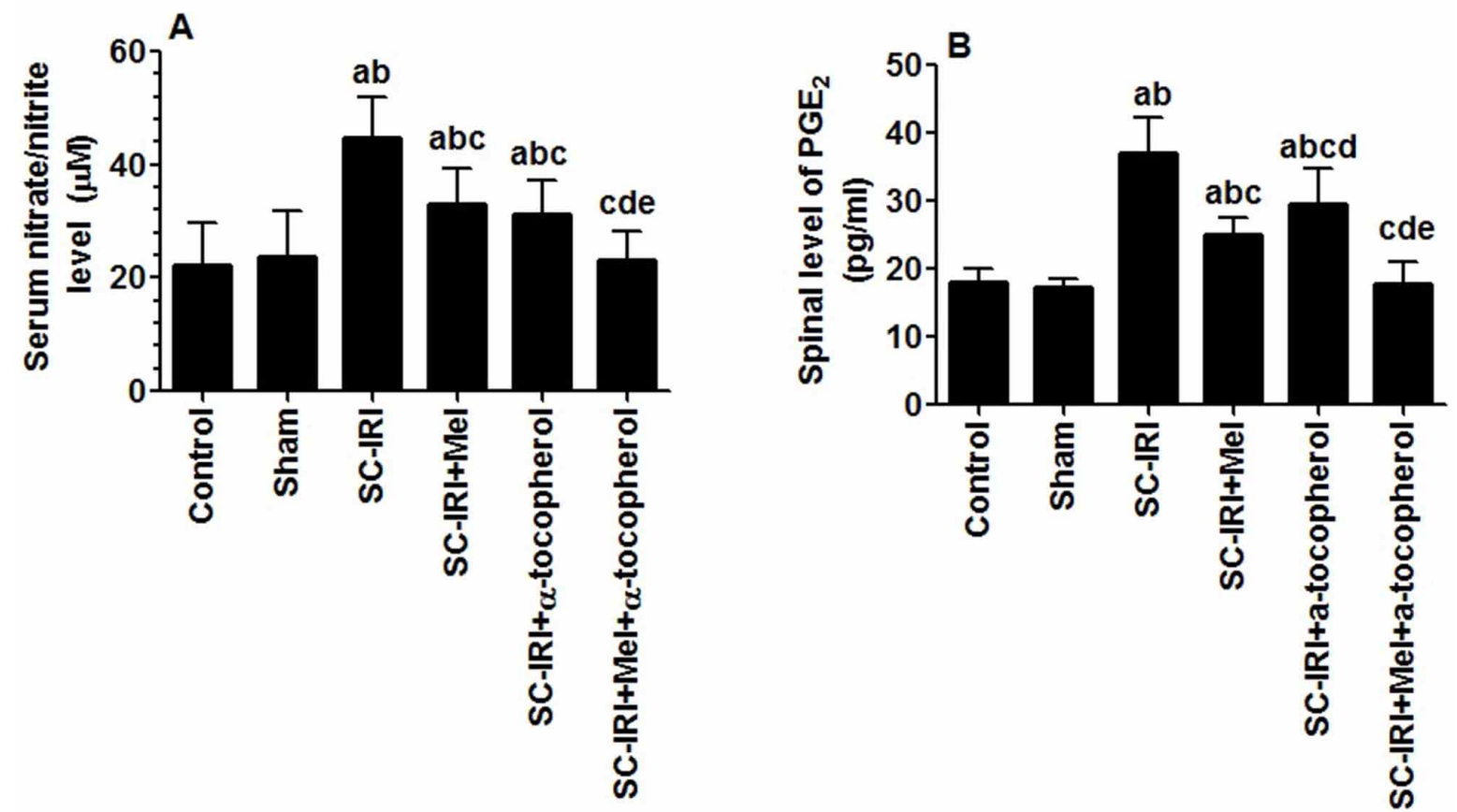

Fig. 1. Effect of melatonin and/or $\alpha$-tocopherol treatment on, nitrate/nitrite and PGE2 (prostaglandin E2) levels in the spinal cord homogenate in different groups. SC-IRI: spinal cord ischemic reperfusion injury group, SC-IRI+Mel: spinal cord ischemic reperfusion injury treated with melatonin group and SC-IRI+Mel+ $\alpha$-tocopherol: spinal cord ischemic reperfusion injury treated with melatonin and $\alpha$-tocopherol group. Results are expressed as means \pm SD. Significance was considered when $P$ value was $<0.05$. a Significantly different from Control group. b Significantly different from Sham group c Significantly different from SC-IRI group. d Significantly different from SC-IRI+Mel group and e Significantly different from SC-IRI+Mel+T group.
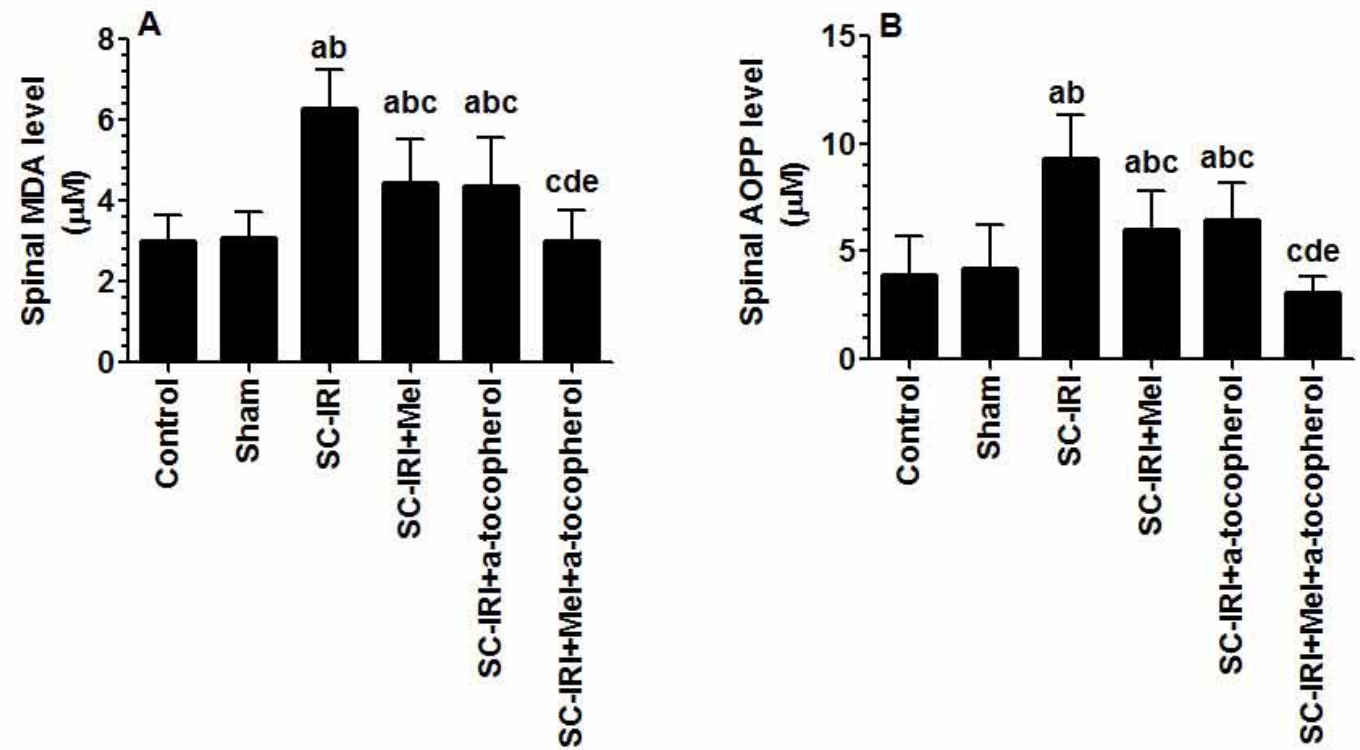

Fig. 2. Effect of melatonin and/or $\alpha$-Tocopherol treatment on MDA (Malondialdehyde) and AOPP (advanced oxidation products) levels in the spinal cord homogenate in different groups. SC-IRI: spinal cord ischemic reperfusion injury group, SC-IRI+Mel: spinal cord ischemic reperfusion injury treated with melatonin group and SC-IRI+Mel+ $\alpha$-tocopherol: spinal cord ischemic reperfusion injury treated with melatonin and $\alpha$-Tocopherol group. Results are expressed as means \pm SD. Significance was considered when $\mathrm{P}$ value was $<0.05$. a Significantly different from Control group. b Significantly different from Sham group c Significantly different from SC-IRI group. d Significantly different from SC-IRI+Mel group and e Significantly different from SC-IRI+Mel+ $\alpha$ tocopherol group. 
significantly increased activities of GSH-Px in the SChomogenates of SC-IRI-treated rats as compared to SC-IRIinduced rats received the vehicle (Figs. 1B, 2 and 3). Again, no significant variation was seen in all these biochemical endpoints when these 2 treated groups were compared with

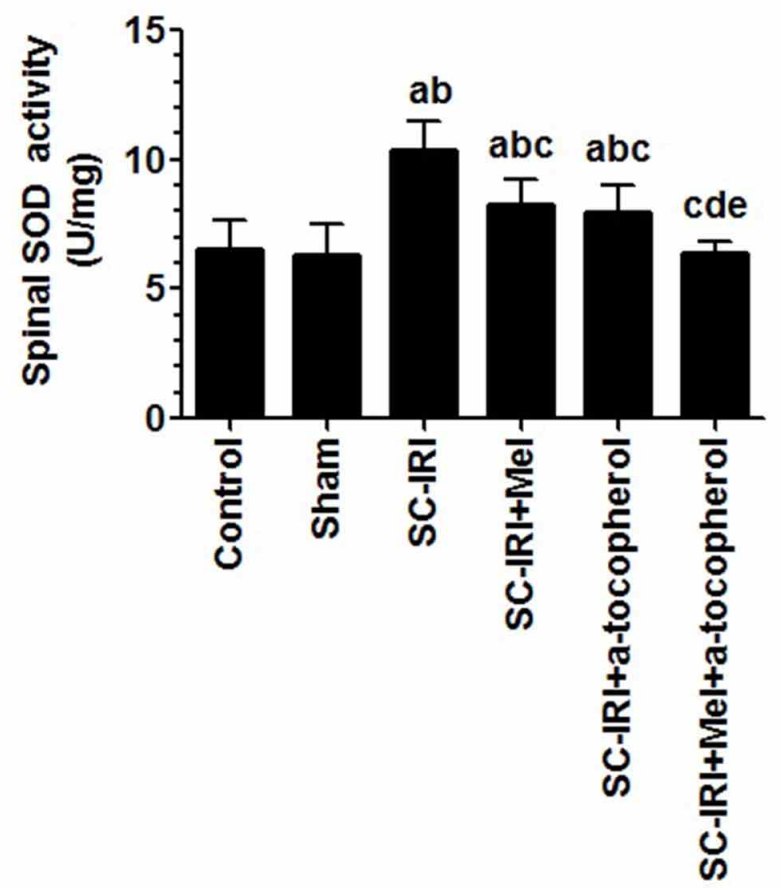

each other (Figs. 1B, 2 and 3). However and as compared to SC-IRI-induced rats, normal levels of PGE2, MDA, and AOPP and activities of SOD and GSH-Px were seen in SCIRI -induced rats received the concomitant doses of both melatonin or $\alpha$-Tocopherol (Figs. 1B, 2 and 3).

Fig. 3. Effect of melatonin and/or $\alpha$-tocopherol treatment on SOD (superoxide dismutase activity) and GSH-GPx (glutathione peroxidase activity) levels in the spinal cord homogenate in different groups. SC-IRI: spinal cord ischemic reperfusion injury group, SC-IRI+Mel: spinal cord ischemic reperfusion injury treated with melatonin group and SC-IRI+ $\alpha$-tocopherol group. Results are expressed as means \pm SD. Significance was considered when $\mathrm{P}$ value was $<0.05$. a Significantly different from control group. $\mathrm{b}$ Significantly different from sham group c Significantly different from SC-IRI group. d Significantly different from SC-IRI+Mel group and e Significantly different from SC-IRI+Mel+ $\alpha$-tocopherol group.
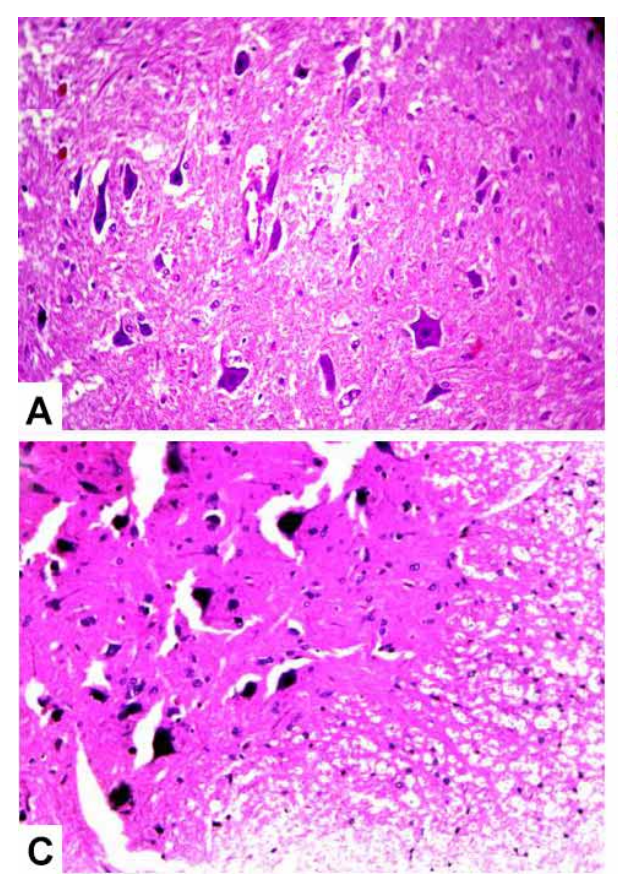

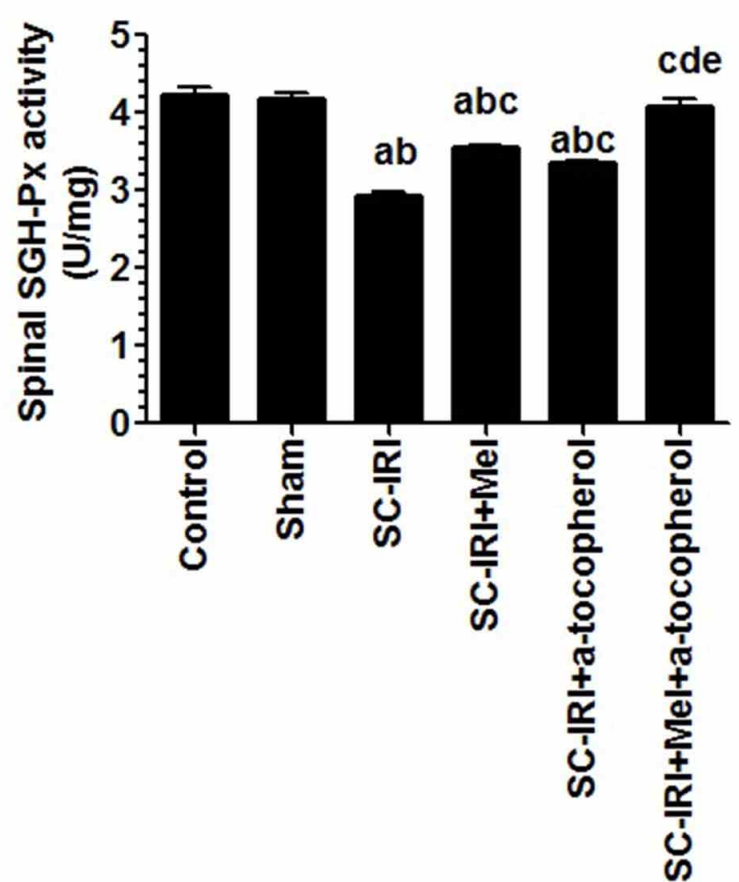


MORSY, M. D.; BASHIR, S. O; AL AGAMY, D. F. \& DIAA, H. A. Protective effect of combined melatonin and $\boldsymbol{\alpha}$-tocopherol administration in spinal cord ischemia-reperfusion injury in rat Int. J. Morphol., 37(2):428-437, 2019.

Histopathological Examination. Figure 4 A and B showed transverse sections of the spinal cord lumber segments 3, 4 and 5 in normal and shame rat`s groups with scattered normal appearing neuronal cells and abundant cytoplasmic nissl substance and cytoplasmic processes. On the other hand, Figure 4C of IRI group showed severe neuronal injury in the lumber segments, most of the neuronal cells showed pyknotic smudged nuclei, invisible nucleoli and shrunken eosinophilic cytoplasm. In Figure $5 \mathrm{~A}$ and B, transverse sections of the spinal cord lumber segments of both SC-IRI+Mel and SC-IRI+ $\alpha$-tocopherol groups showed partial improvement with few scattered viable neuronal bodies and less fragmented degenerated necrotic neuronal cells without great difference between the two groups. Concomitant treated groups in Figure 5C showed frequent more viable neuronal cells with abundant cytoplasm, centrally located nuclei, visible nucleoli and abundant nissl granules and cytoplasmic processes.
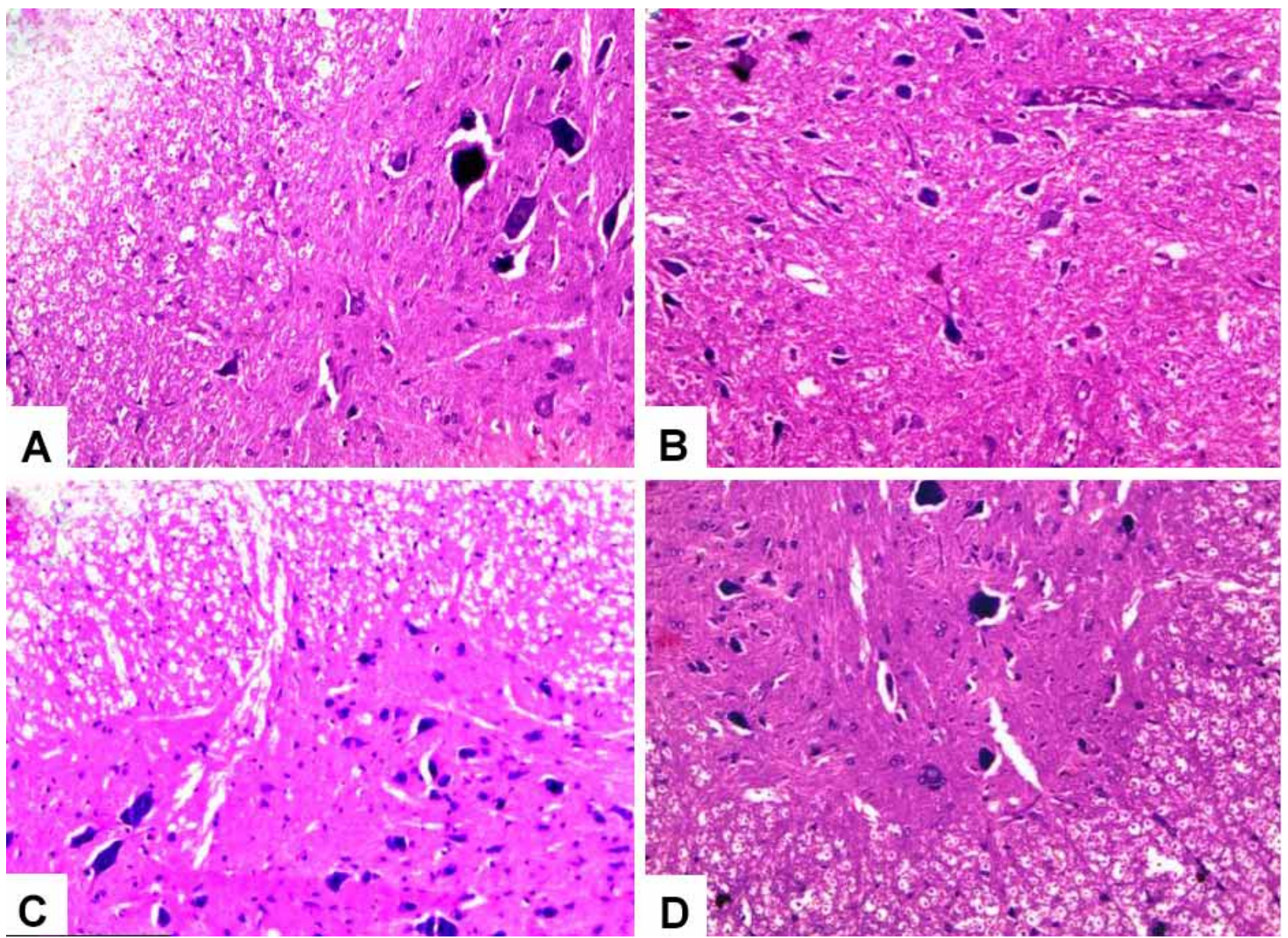

Fig. 5. Spinal cord sections from the lumber 2,3 and 4 segments from the experimental groups (X200). A and B: showing melatonin and $\alpha$-tocopherol treatment effects in the SC-IRI rats subsequently. Both drugs produced less neuronal injury and with less degenerated than SC-IRI group. C: showing the effect of simultaneous treatment with both melatonin and $\alpha$-tocopherol treatment in which more viable neuronal cells with abundant cytoplasm, centrally located nuclei and prominent nucleoli than treatment with each alone, appeared. 
that are able to prevent secondary injury can improve and preserve the anatomical structure of the SC for functional recovery (Rosety-Rodriguez et al.).

In this study, we aimed to investigate and compared the effect of individual or combined administration of two well-known antioxidant and anti-inflammatory drugs on mechanisms involved in the SC secondary injury stage and on hind limbs functional recovery in rats exposed to surgically induced SC-IRI. While both drugs were able to partially improve motor and sensory function of the hind limbs and partially improved all biochemical endpoints measured in the plasma or SC tissue, the exclusive findings of this study indicate a more profound effects of the concomitant administration of melatonin and $\alpha$-tocopherol against SC-IRI induced paraplegia. This has been confirmed by the maximum improvements in motor and sensory function and SPR. This was confirmed by the massive improvement of the neuronal cell bodies in the gray matter in the histological examination of the lumber segments 3,4 and 5 in Figure $5 \mathrm{C}$. while administration of each one individually (either melatonin or $\alpha$-tocopherol) partially improved the neuronal cells of the lumber segments (Fig. 5A,B). Mechanistically, pre-treatment with melatonin and a-tocopherol resulted in the maximum decreases in the inflammatory marker, PGE2, markers of oxidative stress markers including AOPP, SOD and MDA and significant increases in GSH-Px levels in the SC tissue with a parallel maximum decreases in plasma nitrate/nitrite levels.

Oxidative stress and inflammation are the major mechanisms underlying the SC secondary injury post trauma or IRI (Aydemir et al.). Initially superoxide free radicals $(\mathrm{O} 2 \bullet-)$ are operative within first minutes and hours after SCIRI by number of various resources including infiltrating neutrophils and macrophages, over-activation of monoamine oxidase-B activity, auto-oxidation of biogenic amine neurotransmitters including dopamine, norepinephrine, 5hydroxytryptamine), mitochondrial leak, enhanced xanthine oxidase activity, and the oxidation of extravagated hemoglobin, all of which will leads to membranes lipids peroxidation, oxidative damage and more generation of ROS in a self-propagating cycle (Waters et al., 2004). Indeed, it was shown that the SC content of ROS and MDA represents the severity of oxidative stress injury and are a determinant factor for motor and sensory functional recovery (RosetyRodriguez et al.).

Similarly, during early phase post-SCI, a huge number of microglia and inflammatory cells are activated either by IRI itself or by ROS to release a large number of inflammatory factors and activate certain inflammatory target pathways (Yamagata et al., 1993). One of these targets in the neural tissue is COX-2 (Candelario-Jalil \& Fiebich, 2008). COX-2 is one of the major functional enzymes in the neural tissue under physiological conditions to regulate synaptic activity, long-term synaptic plasticity and functional congestion (Wang et al., 2013). However, under pathological conditions such as post-SCI and SCIRI, over-expressed COX-2 was shown to be important in initiating inflammation, pain and cellular damage (Banovac et al., 2004). Furthermore, inflammatory reaction alone or with the action of oxygen free radicals are able to activate neural glial cells to induce the expression of induced nitric oxide synthase (iNOS), leading to higher generation of NO which can easily interact with superoxide ions to form the highly toxic free radical, ONOO-, the most important damaging free radical in acute SCI (Bao \& Liu). This was evidenced in the present study by severe damage of the neuronal cells of the lumber segments of the spinal cord in SC-IRI rats in Figure 4C.

In this regard, inhibiting the oxidative stress response, lipid peroxidation and inflammatory reaction is considered the most important strategy in early treatment for SCI (Schulz et al., 2009) and is the focus of research in the fields of neuroscience, orthopedics and sports medicine (Kaur \& Sanyal; Ellenbroek et al., 2015). Similar protective partial effect on the hind limbs functional recovery, SC oxidative stress parameters and PGE2 levels as well as on plasma levels of total nitrate/nitrite were seen in SC-IRI- induced rats treated with melatonin. This is not surprising given the big history of melatonin as a free radical scavenger, an antioxidant and an immunomodulatory agent in the nervous system including the brain and the SC. Indeed, melatonin is able to a potent free radical scavenger and neutralizer of a large number of ROS and reactive nitrogen species (RNO) (Aydemir et al.). Similar to these findings and due to its antioxidant potentials, melatonin significantly improved motor functional recovery in animal models of SCI by preventing lipid peroxidation and the reduction in intracellular glutathione content (Aydemir et al.). In addition to its antioxidant effects, the significant decreases in serum nitrate/nitrate levels could explain by the inhibitory effect of melatonin on the expression of iNOS mediated by the inhibition of NF-kB activation (Camello-Almaraz et al., 2008).

\section{CONCLUSION}

This study is the first one to demonstrate a possible full recovery of motor and sensory function after concomitant administration of melatonin and $\alpha$-tocopherol in a rat model 
of aortic clamping to induce SC-IRI. This is mediated by the synergistic effects of both drugs to inhibit SC lipid peroxidation, enhance and preserve antioxidant systems, inhibition of COX-2 and reducing PGE2 levels evidenced by the histological examination of the lumber segments.

\section{ACKNOWLEDGMENTS}

The authors highly appreciate the extreme help of all staff members of Abha General Hospital. The authors also thank greatly, Ahmed M Darwesh, Dr. Khalid S Bashir, and Dr. Omar M Morsy for their help in the collection, processing of samples and performing the statistical analysis of data. We extend our thanks to all staff members and technicians of the Physiology and Biochemistry Departments of Colleges of Medicine, King Khalid University, Saudi Arabia, and College of Medicine, Menoufia University, Egypt; for their great help in this work.

\section{FUNDING AND CONFLICT OF INTERESTS}

We would like to thanks the deanship of scientific research, King Khalid University, SA for their funding the research and their help. The authors declare that they have no conflict interests. This research was fully funded by a grant from the deanship of scientific research, King Khalid University, KSA, Project No. 297-2018G-1439H.

MORSY, M. D.; BASHIR, S. O; AL AGAMY, D. F. \& DIAA, H. A. Efecto protector de la administración combinada de melatonina y $\alpha$-tocoferol en la lesión por isquemia-reperfusión de la médula espinal en ratas. Int. J Morphol., 37(2):428-427, 2019.

RESUMEN: El estrés oxidativo y la inflamación son claves en el desarrollo de la disfunción motora posterior a lesión isquémica de la médula espinal (SC-IRI). Este estudio investigó acerca del efecto protector de la administración previa concomitante de la melatonina y alfa-tocoferol en las complicaciones tempranas (después de 48 horas) de la lesión de IRI de la médula espinal en ratas. La melatonina o el $\alpha$-tocoferol se administraron individualmente o en combinación durante 2 semanas, luego las ratas fueron expuestas a SC-IRI. Se evaluaron los exámenes neurológicos de las miembros pélvicos y diversos marcadores bioquímicos de estrés oxidativo e inflamación en el tejido subcutáneo. Solo la administración previa de melatonina o $\alpha$-tocoferol mejoró parcial y significativamente la función motora y sensorial de los miembros pélvicos mediadas por disminuciones parciales en los niveles de SC de los niveles de MDA, AOPP y PGE2 y las actividades de la SOD, disminuciones significativas parciales en los niveles plasmáticos del total nitrato / nitrito y aumentos significativos en la actividad de AC de GSH-Px. Sin embargo, se observaron los mejores resultados durante la combinación de ambos fármacos en todas las evaluaciones neurológicas y en los puntos finales bioquímicos. En conclusión, debido a sus acciones antioxidantes y antiinflamatorias sinérgicas, la terapia de melatonina y $\alpha$-tocoferol alivia la paraplejía inducida por SC-IRI.

PALABRAS CLAVE: Lesión de reperfusión isquémica de la médula espinal; Melatonina, alfa-tocoferol; Estrés oxidativo; Paraplejia.

\section{REFERENCES}

Aghazadeh, S.; Azarnia, M.; Shirazi, A.; Mahdavi, S. R. \& Zangii, B. M. Melatonin as a protective agent in spinal cord damage after gamma irradiation. Rep. Pract. Oncol. Radiother, 12(2):95-9, 2007.

Akgun, S.; Tekeli, A.; Kurtkaya, O.; Civelek, A.; Isbir, S. C.; Ak, K.; Arsan, S. \& Sav, A. (2004). Neuroprotective effects of FK-506, Lcarnitine and azathioprine on spinal cord ischemia-reperfusion injury. Eur. J. Cardiothorac. Surg., 25(1):105-10, 2004.

Aydemir, S.; Dogan, D.; Kocak, A. \& Dilsiz, N. The effect of melatonin on spinal cord after ischemia in rats. Spinal Cord, 54(4):360-3, 2016.

Banovac, K.; Williams, J. M.; Patrick, L. D. \& Levi, A. Prevention of heterotopic ossification after spinal cord injury with COX-2 selective inhibitor (rofecoxib). Spinal Cord, 42(12):707-10, 2004.

Bao, F. \& Liu, D. Peroxynitrite generated in the rat spinal cord induces apoptotic cell death and activates caspase-3. Neuroscience, 116(1):5970, 2003.

Bashir, S. O.; Mostafa, O. A.; Rizk, M. S.; Al-Ridi, M. R. \& Morsy, M. D. Intestinal ischemic preconditioning modulates oxidative stress in rat's spinal cord ischemic reperfusion injury. Am. J. Biomed. Sci., 4(3):220-32, 2012.

Bernes, P. J. \& Karin, M. Nuclear factor-kappaB: a pivotal transcription factor in chronic inflammatory diseases. N. Engl. J. Med., 336(15):1066-71, 1997.

Birben, E.; Sahiner, U. M.; Sackesen, C.; Erzurum, S. \& Kalayci, O. Oxidative stress and antioxidant defense. World Allergy Organ. J., 5(1):9-19, 2012.

Camello-Almaraz, C.; Gomez-Pinilla, P. J.; Pozo, M. J. \& Camello, P. J. Age-related alterations in $\mathrm{Ca} 2+$ signals and mitochondrial membrane potential in exocrine cells are prevented by melatonin. J. Pineal Res., 45(2):191-8, 2008.

Candelario-Jalil, E. \& Fiebich, B. L. Cyclooxygenase inhibition in ischemic brain injury. Curr. Pharm. Des., 14(14):1401-18, 2008.

de Rivero Vaccari, J. P.; Marcillo, A.; Nonner, D.; Dietrich, W. D. \& Keane, R. W. Neuroprotective effects of bone morphogenetic protein 7 (BMP7) treatment after spinal cord injury. Neurosci. Lett., 465(3):226-9, 2009.

Ellenbroek, D.; Kressler, J.; Cowan, R. E.; Burns, P. A.; Mendez, A. J. \& Nash, M. S. Effects of prandial challenge on triglyceridemia, glycemia, and pro-inflammatory activity in persons with chronic paraplegia. J. Spinal Cord Med., 38(4):468-75, 2015.

Gül, S.; Celik, S. E.; Kalayci, M.; Tas „yürekli, M.; Cokar, N. \& Bilge, T. Dose-dependent neuroprotective effects of melatonin on experimental spinal cord injury in rats. Surg. Neurol., 64(4):355-61, 2005.

Iwasa, K. \& Ikata, T. An experimental study on preventive effect of vitamin E in spinal cord injury. Nihon Seikeigeka Gakkai Zasshi, 62(8):767-75, 1988.

Iwasa, K.; Ikata, T. \& Fukuzawa, K. Protective effect of vitamin E on spinal cord injury by compression and concurrent lipid peroxidation. Free Radic. Biol. Med., 6(6):599-606, 1989. 
Kaur, J. \& Sanyal, S. N. Oxidative stress and stress-signaling in chemoprevention of early colon cancer by diclofenac. Am. J. Biomed. Sci., 2(1):63-78, 2010.

Marsala, M. \& Yaksh, T. L. Transient spinal ischemia in the rat: characterization of behavioral and histopathological consequences as a function of the duration of aortic occlusion. J. Cereb. Blood Flow Metab., 14(3):526-35, 1994.

Morsy, M. D.; Mostafa, O. A. \& Hassan, W. N. A potential protective effect of a-tocopherol on vascular complication in spinal cord reperfusion injury in rats. J. Biomed. Sci., 17(1):55, 2010.

Rosety-Rodriguez, M.; Camacho, A.; Rosety, I.; Fornieles, G.; Rosety, M. A.; Diaz, A. J.; Bernardi, M.; Rosety, M. \& Ordonez, F. J. Lowgrade systemic inflammation and leptin levels were improved by arm cranking exercise in adults with chronic spinal cord injury. Arch. Phys. Med. Rehabil., 95(2):297-302, 2014.

Saito, T.; Tsuchida, M.; Umehara, S.; Kohno, T.; Yamamoto, H. \& Hayashi, J. Reduction of spinal cord ischemia/reperfusion injury with simvastatin in rats. Anesth. Analg., 113(3):565-71, 2011.

Sakurai, M.; Hayashi, T.; Abe, K.; Aoki, M.; Sadahiro, M. \& Tabayashi, $\mathrm{K}$. Enhancement of heat shock protein expression after transient ischemia in the preconditioned spinal cord of rabbits. J. Vasc. Surg., 27(4):720-5, 1998.

Schulz, R.; Czaja, S. J.; Lustig, A.; Zdaniuk, B.; Martire, L. M. \& Perdomo, D. Improving the quality of life of caregivers of persons with spinal cord injury: a randomized controlled trial. Rehabil. Psychol., 54(1):1-15, 2009.

Silva, M. G.; Castro, A. A.; Ramos, E. A.; Peixoto, E.; Miranda, F. Jr.; Pitta, G. de B.; Costa, R. de F. \& Juliano, Y. Histological and biochemical serum effects of alpha-tocopherol on ischemia/ reperfusion-related injuries induced in the pelvic limb of rats. Acta Cir. Bras., 20(5):375-81, 2005.

Szczepanik, M. Melatonin and its influence on immune system. $J$. Physiol. Pharmacol., 58 Suppl. 6:115-24, 2007.

Tan, D. X.; Manchester, L. C.; Reiter, R. J.; Plummer, B. F.; Limson, J.; Weintraub, S. T. \& Qi, W. Melatonin directly scavenges hydrogen peroxide: a potentially new metabolic pathway of melatonin biotransformation. Free Radic. Biol. Med., 29(11):117785, 2000.

Tan, D. X.; Manchester, L. C.; Terron, M. P.; Flores, L. J. \& Reiter, R. $\mathrm{J}$. One molecule, many derivatives: a never-ending interaction of melatonin with reactive oxygen and nitrogen species? J. Pineal Res., 42(1):28-42, 2007.

Tarlov, I. M. Acute spinal cord compression paralysis. J. Neurosurg., 36(1):10-20, 1972.

Wang, G.; Huang, C.; Wang, Y.; Guo, Q.; Jiang, H. \& Wen, J. Changes in expression of cyclooxygenase-2 in the spinal dorsal horn after intrathecal p38MAPK inhibitor SB203580 on neuropathic pain in rats. Zhong Nan Da Хие Хие Baо Yi Хие Ban, 38(7):686-90, 2013.

Waters, S.; Fae, A.; Gondalia, J.; Holm, J.; Karlström, L.; Nilsson, U. \& Jonsson, O. Effects of pretreatment with a xanthine oxidase inhibitor on free radical levels during carotid endarterectomy. Free Radic. Res., 38(3):283-93, 2004.

Wilson, J. R.; Grossman, R. G.; Frankowski, R. F.; Kiss, A.; Davis, A. M.; Kulkarni, A. V.; Harrop, J. S.; Aarabi, B.; Vaccaro, A.; Tator, C. H.; Dvorak, M.; Shaffrey, C. I.; Harkema, S.; Guest, J. D. \& Fehlings, M. G. A clinical prediction model for long-term functional outcome after traumatic spinal cord injury based on acute clinical and imaging factors. J. Neurotrauma, 29(13):2263-71, 2012.

Wu, Q.; Jing, Y.; Yuan, X.; Zhang, X.; Li, B.; Liu, M.; Wang, B.; Li, H.; Liu, S. \& Xiu, R. Melatonin treatment protects against acute spinal cord injury-induced disruption of blood spinal cord barrier in mice. J. Mol, Neurosci., 54(4):714-22, 2014.

Yamagata, K.; Andreasson, K. I.; Kaufmann, W. E.; Barnes, C. A. \& Worley, P. F. Expression of a mitogen-inducible cyclooxygenase in brain neurons: regulation by synaptic activity and glucocorticoids. Neuron, 11(2):371-86, 1993.

Yang, L.; Yao, M.; Lan, Y.; Mo, W.; Sun, Y. L.; Wang, J.; Wang, Y. J. \& Cui, X. J. Melatonin for Spinal Cord Injury in Animal Models: A Systematic Review and Network Meta-Analysis. J. Neurotrauma, 33(3):290-300, 2016.

Zhang, S. X.; Huang, F.; Gates, M. \& Holmberg, E. G. Role of endogenous Schwann cells in tissue repair after spinal cord injury. Neural Regen. Res., 8(2):177-85, 2013.

\section{Corresponding author: Mohamed Darwesh Morsy \\ Department of Physiology \\ College of Medicine \\ King Khalid University \\ Abha \\ 61421 \\ SAUDI ARABIA}

\section{E-mail: morsydarwesh@yahoo.com}

Received: 25-09-2018

Accepted: 02-01-2019 